\title{
Human Genetic Association Studies: association between of Human genome with Clinical outcome
}

\author{
Fahmida Khatoon ${ }^{1 *}$ and Farhan Essa Abdullah ${ }^{2}$ \\ ${ }^{1}$ Department of Biochemistry, University of Hail, Saudi Arabia \\ ${ }^{2}$ Department of Microbiology, Essa laboratory and Diagnostic Centre, Pakistan \\ Submission: January 30, 2018; Published: August 10, 2018 \\ *Corresponding author: Fahmida Khatoon, Department of Biochemistry, Faculty of Medicine, University of Hail, Saudi Arabia; \\ Email: fahmida.khatoon@yahoo.com
}

\begin{abstract}
The achievements of Human Genome Project and subsequent advancements in Genotyping have led to an influx of exciting new developments in genetics. Technology has provided scientists with a comprehensive data on human genomes as human genome is now capable to incite in depth and precise data information that allows access to detailed DNA sequences in order to analyze clinical questions. The methods employed have been optimized to examine the application of Genome Wide Association Studies with population based forensic investigations. Genome Wide Association Studies associated approaches have also been incorporated in routine clinical practice.

Keywords: Genome project; Genetics; Approaches; Clinical practice; Achievements; Population; Nucleotide polymorphisms; Homogenous; Equilibrium; Ethnogeographic; Huntington Disease; Fibrosis; Inheritance; Pathological; Geographic; Correlation; European; Heritage; Phenotypes; Capable
\end{abstract}

Abbreviations: QC: Quantity Check; SNP: Single Nucleotide Polymorphisms

\section{Mini Review}

The use of Genome Wide Association Studies for detecting many diseases of forensic interest and traits for sex distributions are due to sex associated variations in prevalence [1]. The sex and ancestry related data and genetic information are important components for Quantity Check (QC) in GWAS and can be implemented in practice to remove misidentifications of samples and stratifications in population samples. The approach to identify the mis-identification in processes where strong associations are detected between genotype and phenotype characteristics can be inferred if the observed phenotype is expected to be caused by the observed genotype for every subject within the study[2].

The study of genomic and associated genetic markers requires the step wise following of techniques like firstly, a set of information about genotype and phenotype relationship need to be established and identified[2]. Secondly, phenotypes need to be ascertained at additional cost before the initiation of study, possibly for reasons of extracting usual phenotype data during the collection method. Thirdly, the modeling for the mixture sample that is under consideration for estimating phenotype and genotype relationship needs to be optimized to deliver highest set of information. Finally, the combination of all the information assessed from the relationships should be higher enough to give better sensitivity and specificity. It can also be possible to assess Single Nucleotide Polymorphisms (SNPs) in determining genotype for each sample, before the execution of costly Genome Associated Studies or Genome Sequencing into practice[2].

\section{Ancestral sampling in genome wide association stud-} ies

Global studies like Jakobsson et al.in 2008[3]reveal that genome wide population structure on various levels can be assessed using statistical approaches. Individuals in different continents are differentiated in genetic framework through genome-wide SNP data but however, some level of overlapping do exist between continental regions[3]. This genetic overlapping increases with decreasing distances between continental regions. For example, there is a strong relationship between geographic correlation and genetics similarity of an individual who resides in Europe, but there is a considerable overlap of genetic similarity among neighboring European subpopulations which determines accurate determinations for genetic variability[4]. 
Phenotypical Variance Incorporated into Genomic Studies and SNPsthe genetic effect of Single Nucleotide Polymorphisms (SNPs) on the phenotype of an individual depends on the number of contributing SNPs and non-genetic influences like environmental effects, in determining accurately an identity of a person. Phenotype studies illustrate that eye color is the most successfully predictable phenotype essential in accurately identifying basic physical factors in an individual. The challenges undertaken in applying DNA prediction into categorizing appearance traits and eye color is its expected variability in conceptual understanding of trait information. For example, people assign same eye color to various color categories and therefore look different from others using an eye color provided by DNA predictions. In order to minimize this problem, studies investigated about the genetic basis of variation in eye color utilizing SNP data analysis[5,6].

\section{Structured association and genetic markers in GWAS}

The technique of Structured Association works on the principle of Hardy and Weinberg's Equilibrium within populations with linkages to genetic markers that are also responsible for establishing equilibrium to detect and correct stratification in a homogenous sub group cluster based on genotypic characteristics. Test for detecting familial or hereditary pathological traits in the generations can be achieved by studying association of each genetic marker to disease expression phenotype [7].

\section{Failures of linkage for complex disease}

Cystic fibrosis (and most rare genetic disorders) can be caused by multiple different genetic variants within a single gene. Because the effect of the genetic variants is so strong, cystic fibrosis follows an autosomal dominant inheritance pattern in families with the disorder. One of the major successes of human genetics was the identification of multiple mutations in the CFTR gene as the cause of cystic fibrosisThis was achieved by genotyping families affected by cystic fibrosis using a collection of genetic markers across the genome and examining how those genetic markers segregate with the disease across multiple families. This technique, called linkage analysis, was subsequently applied successfully to identify genetic variants that contribute to rare disorders like Huntington disease $[8,9]$.

\section{Conclusion}

Over the span of last 10 years, the fields of genomics have under taken interesting and dramatic shifts in how to comprehend forensic detailing with respect to investigations about unknown pedigree, unidentified complex diseases and ethnogeographic ancestry of subjectsas studied by Scott, in[10] The wealth of information which can be extracted from immense map of human genome along with advancements in genotyping and related technologies has presented many opportunities for the scientists to test assumptions about the complex genomics for human. This has led a new era of genetic investigation like Genomic Association studies that incorporates to solve analytical questions about heritage and population-based studies.

\section{Future Direction}

Genome-wide association studies have identified new genetic risk factors for many common human diseases and have forced the genetics community to think on a genome-wide scale. Looking towards the future, it seems evident that the current enhancements in Genome Wide Association Studies is going to transform through changes for finding genetic susceptibilities that are responsible for causing characteristics unique to a familial trait[11].In 2010, Durbin provided a series of projects in the ' 1000 Genomic Project' that has provided an avenue for testing assumptions by utilizing sequencing techniques to identify rare variations in human genome. The use of sequential data for detecting rare genes for variant determination has also been observed possible through association analysis.

\section{References}

1. Laurie CC, Doheny KF, Mirel DB, Pugh EW, Bierut LJ, et al. (2010) Quality control and quality assurance in genotypic data for genomewide association studies. Genet Epidemiol 34(6): 591-602.

2. Hindorff L, Junkins H, Hall P, Mehta J, Manolio T (2009) A catalog of published genome-wide association studies.

3. Jakobsson M, Scholz SW, Scheet P, Gibbs JR, VanLiere JM, et al. (2008) Genotype, haplotype and copy number variation in worldwide human populations. Nature 451(7181): 998-1003.

4. Johnson AD, Leslie R, O'Donnell C J (2011) Temporal Trends in Results Availability from Genome-Wide Association Studies. Plos Genet 7(9): e1002269.

5. Mangold E, Ludwig KU, Birnbaum S, Baluardo C, Ferrian M, et al. (2010) Genome wide association study identifies two susceptibility loci for nonsyndromic cleft lip with or without cleft palate. Nat Genet 42(1): $24-26$.

6. Safar HS, Abidi FH, Khazanehdari K A, Dadour IR, Tay G K (2011) Evaluation of different sources of DNA for use in genome wide studies and forensic application. Applied Microbiology \& Biotechnology 89(3): 807-815.

7. Alexander DH, Novembre J, Lange K (2009) Fast Model-Based Estimation of Ancestry in Unrelated Individuals. Genome Res 19 (9): 1655-1664.

8. Kerem B, Rommens JM, Buchanan JA, Markiewicz D, Cox TK, et al. (1989) Identification of the cystic fibrosis gene: genetic analysis. Science 245(4922): 1073-1080.

9. MacDonald ME, Novelletto A, Lin C, Tagle D, Barnes G, et al. (1992) The Huntington's disease candidate region exhibits many different haplotypes. Nat Genet 1(2): 99-103.

10. Scott RC, Juhasz G, Neufeld TP (2007) Direct induction of autophagy by Atg1 inhibits cell growth and induces apoptotic cell death. Curr Biol 17(1):1-11.

11. Bird T D (2005) Genetic Factors in Alzheimer's Disease. N Engl J Med 352 (9): 862-864. 
This work is licensed under Creative Commons Attribution 4.0 Licens DOI: 10.19080/AIBM.2018.10.555778
Your next submission with Juniper Publishers will reach you the below assets

- Quality Editorial service

- Swift Peer Review

- Reprints availability

- E-prints Service

- Manuscript Podcast for convenient understanding

- Global attainment for your research

- Manuscript accessibility in different formats ( Pdf, E-pub, Full Text, Audio)

- Unceasing customer service

Track the below URL for one-step submission https://juniperpublishers.com/online-submission.php 